\title{
Dependência espacial do ruído de tratores agrícolas em diferentes rotações do motor
}

\author{
Emanuel Rangel Spadim ${ }^{1}$, Indiamara Marasca ${ }^{1}$, Murilo Martins Batistuzzi ${ }^{1}$, Marcelo \\ Scantaburlo Denadai ${ }^{1}$, Saulo Philipe Sebastião Guerra ${ }^{1}$
}

${ }^{1}$ Faculdade de Ciências Agronômicas da Universidade Estadual Paulista Júlio de Mesquita Filho-UNESP, Botucatu, SP, Brasil. Email: spadim@gmail.com, marasca_7@hotmail.com,mbm_martins@hotmail.com,msdenadai@hotmail.com, ssguerra@fca.unesp.br

Recebido: 23/07/2015; Aceito: 15/09/2015

\section{RESUMO}

Diversos elementos afetam a saúde do trabalhador, sendo o ruído um importante fator causador de estresse e prejudicial aos operadores expostos por muitas horas à tais ruídos elevados. O objetivo do trabalho foi de quantificar e dimensionar a amplitude dos valores de ruído em diferentes rotações de dois tratores agrícolas. O ensaio foi realizado nas dependências do Núcleo de Ensaio de Máquinas e Pneus Agroflorestais, Faculdade de Ciências Agronômicas, UNESP de Botucatu/SP. O ruído foi mensurado com um decibelímetro marca Icel modelo DL-4200. Utilizou-se dois tratores de $78 \mathrm{cv}$ de potência. As rotações escolhidas foram a rotação de $2200 \mathrm{rpm}$ e a de $2400 \mathrm{rpm}$. Os valores de ruído foram analisados por geoestatística. Para a construção dos mapas temáticos, utilizou-se o software Surfer. A variabilidade espacial do ruído em torno do trator teve maior alcance na plena aceleração com $31 \mathrm{~m}$. Os valores de ruído superiores a $85 \mathrm{~dB}$ foram encontrados numa distância de $7 \mathrm{~m}$ para rotação de trabalho e $11 \mathrm{~m}$ para plena aceleração em relação ao trator. Os valores encontrados nessas distâncias são considerados prejudiciais para os operadores das máquinas e para indivíduos que permaneçam próximos ao trator segundo a norma NR 15.

Palavras-chave: espacialidade, geoestatística, mecanização, norma, NR 15.

\section{Spatial dependence of noise in different agricultural tractors engine revolutions}

\section{ABSTRACT}

Several elements affect workers' health, and the noise was a major factor causing stress and harmful to operators, which are exposed for many hours to loud noises. The objective was to quantify and measure the amplitude of the noise values at different speeds from two tractors. The test was conducted on the premises of Machinery Test Center and Agroforestry tires, Faculty of Agricultural Sciences, Botucatu/SP, UNESP. The noise was measured with a decibel meter mark Icel model DL-4200. We used two tractors of 78 horsepower, three-cylinder, turbo and open cockpit. The rotations were chosen speed $2200 \mathrm{rpm}$ and $2400 \mathrm{rpm}$. The noise values were analyzed geostatistical. The spatial variability of noise around the tractor had greater reach in full throttle with $31 \mathrm{~m}$. The noise values in excess of $85 \mathrm{~dB}$ were found within $7 \mathrm{~m}$ to working speed and full throttle to $11 \mathrm{~m}$ in relation to the tractor. The values found in these distances are considered prejudicial to machine operators and for individuals to remain near the tractor according to the standard NR 15.

Keywords: Spatiality, geostatistics, mechanization, norm, NR15. 


\section{Introdução}

As máquinas que são utilizadas para diversas atividades, na maioria das vezes, importadas ou adaptadas não são adequadas às operações e condições brasileiras. De custos elevados, exigindo o máximo de aproveitamento de todas as suas funções, muitas vezes menosprezam as condições de trabalho ou simplesmente não atendem as normas nacionais vigentes, relegando os princípios ergonômicos.

Dentre os inúmeros fatores inerentes às máquinas, que podem ser prejudiciais ao homem, destaca-se o ruído, sendo este o foco do presente trabalho. $\mathrm{O}$ aumento da ênfase na poluição do ar, poluição da água e da qualidade ambiental em geral, criou a necessidade de analisar o ambiente acústico que rodeia o homem, especialmente no posto de operação do operador (BRAVALHERI et al., 2010).

Entre os fatores ergonômicos que prejudicam os operadores das máquinas, o ruído pode ser considerado um dos principais, com o agravante de existirem poucos trabalhos desenvolvidos para a avaliação deste parâmetro e suas implicações na saúde ocupacional (CUNHA; TEODORO, 2006).

No Brasil, a Associação Brasileira de Normas Técnicas (ABNT), possui algumas normas técnicas sobre medições de ruídos em máquinas agrícolas, destacando a NBR 9999 e a NBR-1052, que estabelece os níveis de ruído para o conforto acústico, e a NR 15 da portaria 3214/78, do Ministério do Trabalho e Emprego (MTb), referente às atividades de operações insalubres, estabelecendo o nível máximo de ruído de 85 decibéis $(\mathrm{dB})$ para exposição diária de 8 horas (BRASIL, 2014).

Com a modernização da agricultura, a expansão da mecanização agrícola foi evidentemente contribuindo com um ambiente de trabalho mais arriscado e insalubre aos trabalhadores rurais. A utilização dos Equipamentos de Proteção Individual (EPI), formação escolar, idade, treinamento dos trabalhadores, programas de prevenção de acidentes e conscientização, são fatores de suma importância para prevenção e redução dos acidentes de trabalho nas atividades agrícolas (AMBROSI; MAGGI, 2013).

Em condições de campo, os níveis de ruído próximos ao operador são superiores aos estabelecidos pelas normas, para a exposição diária, sem o uso de protetor auricular. Á medida que se aumenta a rotação do motor do trator há incremento linear do nível de potência sonora, sendo que, a partir de 1000 rpm, há necessidade de uso de proteção auricular (ALVES et al., 2011).

Este trabalho teve como objetivo quantificar e dimensionara amplitude dos valores de ruído em diferentes rotações de dois tratores agrícolas.

\section{Material e Métodos}

O experimento foi realizado nas dependências do Núcleo de Ensaio de Máquinas e Pneus Agroflorestais (NEMPA), situado na Faculdade de Ciências Agronômicas, UNESP de Botucatu/SP. Utilizou-se dois tratores de pequeno porte com motor de $78 \mathrm{cv}$ de potência (ISO14396), três cilindros, turbo, cabine aberta e 100 horas de uso. As rotações escolhidas foram a rotação de trabalho de 2200rpm e a de plena aceleração de 2400rpm.

A malha amostral escolhida foi do tipo "homogênea" e, a fim de se tornar mais simples e precisa a leitura da posição dos pontos de amostragem, a área foi delimitada por um quadrado de 42 metros de lado, contido em um plano cartesiano imaginário. Os tratores foram posicionados no centro deste quadrado, sendo ensaiados em dois momentos diferentes.

A cada $6 \mathrm{~m}$ foram traçadas retas perpendiculares aos eixos que definiam o plano, sendo as distâncias determinadas com uma trena convencional. Os cruzamentos destas retas determinaram as coordenadas dos pontos de amostragem, totalizando 64 pontos de coleta.

O local escolhido foi uma área ao ar livre, plana e isenta de ruídos externos que poderiam intervir no experimento. O receptor GPS pelo qual se observou a posição da área de ensaio foi da marca Garmin, modelo GPSMAP 60CSx. O aparelho utilizado para medir o ruído gerado pela máquina foi um decibelímetro da marca Icel, modelo DL-4200, conforme Figura 1.

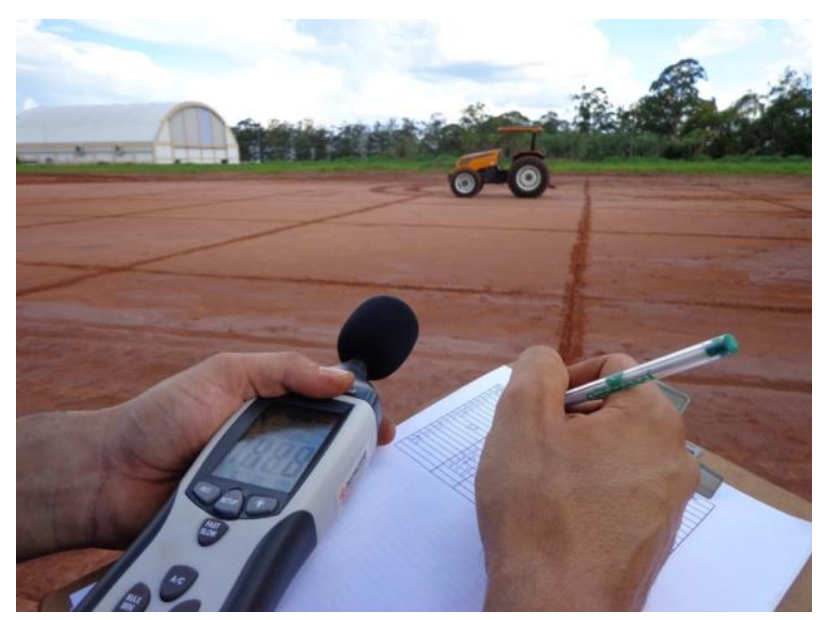

Figura 1. Decibelímetro, malha amostral e trator utilizado para realização do trabalho.

O decibelímetro utilizado atende aos padrões da "International Electrotechnical Commission Standards IEC 60651:1979; Amd1:1993; Amd2:2000” em resposta lenta, o qual esteve, em todas as coletas, com o microfone voltado para o trator, e à altura dos ouvidos de um indivíduo de estatura média, 1,7m.

A bola de espuma atua como proteção de vento para o microfone do decibelímetro. A escala dos mapas foi 
ajustada em dB por ser a escala convencionalmente utilizada nos ensaios de ruído de tratores, e por melhor representar a curva de resposta do ouvido humano. O software utilizado para geração dos mapas e cálculo da área ocupada pelos níveis de ruído foi o Surfer 9.1.352.

\section{Resultados e Discussão}

A metodologia para interpolação dos dados utilizada foi a Krigagem ordinária, resultando em uma abrangência de $42 \mathrm{~m}$. O método de Krigagem visa estimar o valor de um fenômeno em posições não amostradas, utilizando informações provenientes de dados amostrados da variável em posições vizinhas.

Este método utiliza um conjunto de técnicas de regressão linear generalizada para minimizar os erros de predição, produzindo uma estimativa não enviesada (DEUTSCH; JOUMEL, 1998). A técnica da Krigagem da variável indicadora tem sido aplicada na geração de mapas de probabilidade. A variável aleatória é transformada em uma variável indicadora e esta é estimada em pontos não amostrados. Na realidade, a variável indicadora é obtida para cada teor de corte dentro dos limites da distribuição de frequências (YAMAMOTO, 2010).
Os resultados da análise geoestatística (Tabela 1), mostraram que todas as rotações analisadas apresentaram dependência espacial na escala de amostragem adotada.

Diferente do modelo encontrado neste trabalho, Ferraz et al. (2013) encontraram modelo esférico para o comportamento ruído de uma derriçadora. Quanto ao grau de dependência espacial (IDE), as duas rotações avaliadas apresentaram forte dependência espacial, segundo classificação de ZIMBACK (2001).

Os parâmetros do variograma são intervalo da distância em que o variograma atinge o limiar, ou seja, é a distância que a variável apresenta dependência espacial, efeito pepita reflete a erro analítico, indicando uma variabilidade inexplicada de um ponto a outro, o que pode ser devido tanto a erros nas medições ou micro variações não detectadas devido à distância de amostragem, componente estrutural quanto a variação depende da distância, limiar valor em que o variograma é estabilizada e é, aproximadamente, igual à da variância dos dados (SILVA et al., 2013).

Na Figura 2, são apresentados os mapas temáticos para a distribuição do ruído em função da rotação aceleração de 2200 e na Figura 3 para a aceleração de máxima (2400rpm), construídos por krigagem ordinária.

Tabela 1. Semivariograma e parâmetros de ajuste para diferentes rotações de dois tratores agrícolas.

\begin{tabular}{llllllll}
\hline Trator & Rotações & Modelo & $\mathrm{A}(\mathrm{m})$ & $\mathrm{C} 0$ & $\mathrm{C} 0+\mathrm{C}$ & $\mathrm{IDE}(\%)$ & $\mathrm{R}^{2}(\%)$ \\
\hline $\mathrm{A}$ & 2200 & Gaussiano & 23,74 & 0,1 & 35,52 & 99 & 97 \\
$\mathrm{~B}$ & 2200 & Gaussiano & 23,53 & 0,1 & 31,92 & 99 & 98 \\
$\mathrm{~A}$ & 2400 & Gaussiano & 23,91 & 0,01 & 31,01 & 100 & 97 \\
B & 2400 & Gaussiano & 22,89 & 0,1 & 34,48 & 99 & 97 \\
\hline
\end{tabular}

A (m) - alcance; C0 - Efeito pepita; C0+C: Patamar; IDE (\%): Índice dependência espacial; R2 (\%): Coeficiente de determinação múltipla do ajuste.

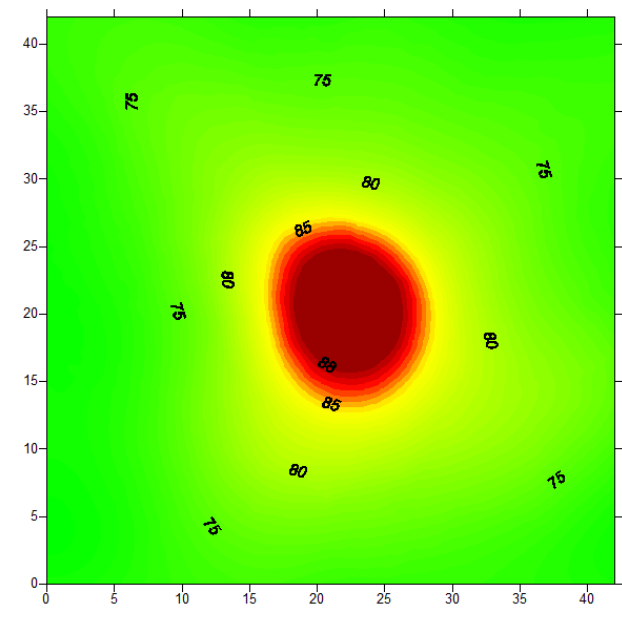

(a)

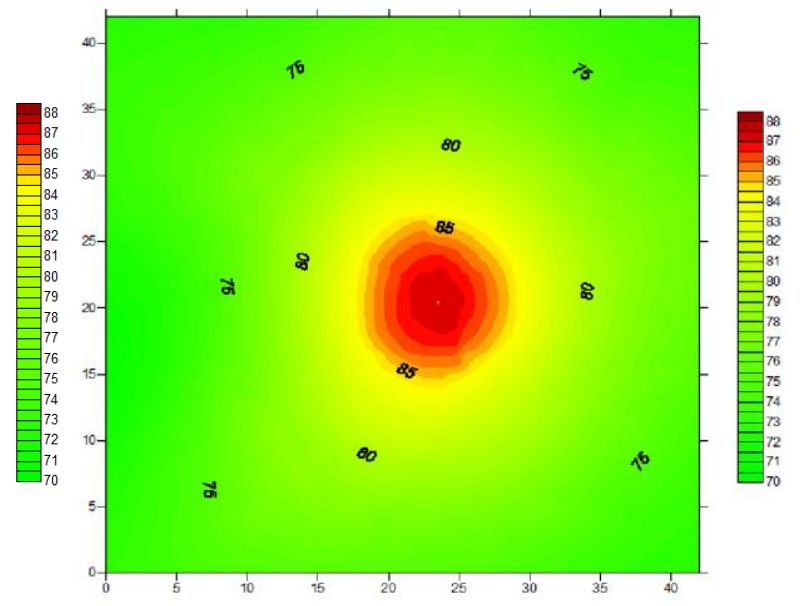

(b)

Figura 2. Mapas de interpolação de ruído para aceleração de 2200 rpm para os tratores A (a) e B (b). 


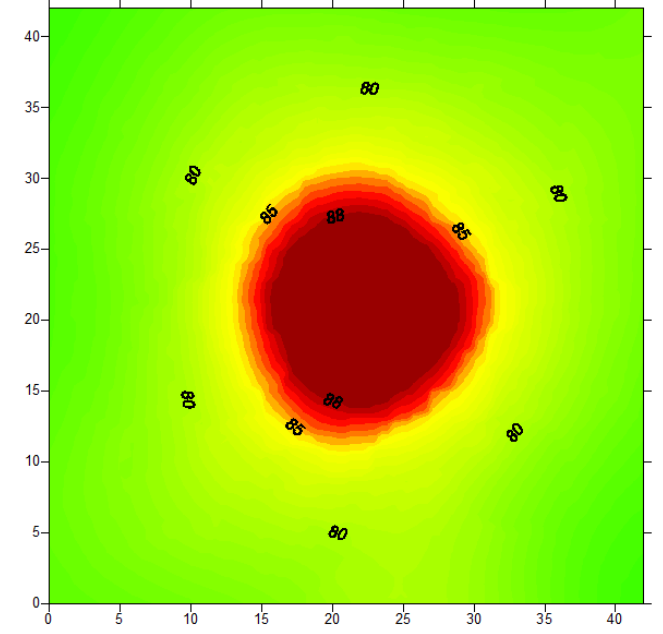

(a)

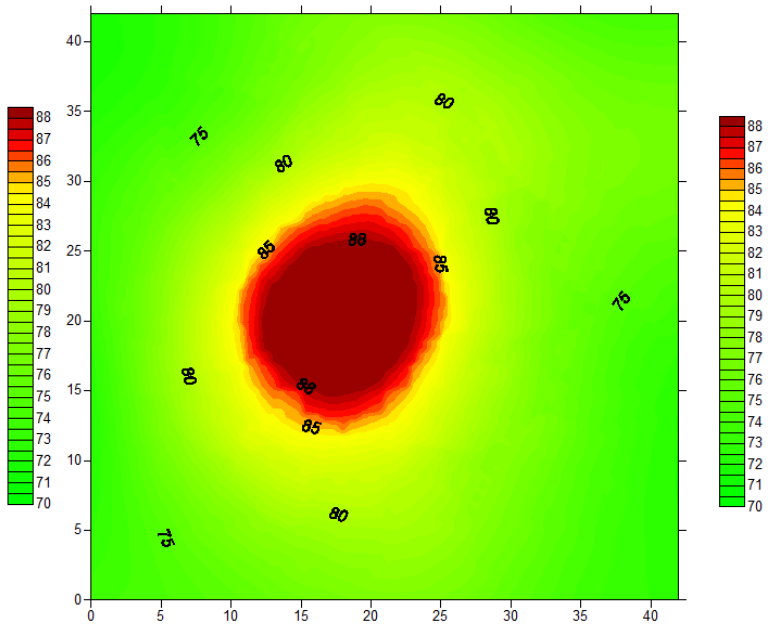

(b)

Figura 3. Mapas de interpolação de ruído para aceleração de máxima (2400 rpm) nos tratores A (a) e B (b).

Segundo a NR-15, a exposição às vibrações acima dos limites de tolerância é considerada uma insalubridade de grau médio. Porém Yanagi Junior et al. (2012) encontrou ajuste ao mesmo modelo desta pesquisa e consideraram possível caracterizar a variabilidade espacial da magnitude dos dados de ruído avaliadas com máquinas, derriçadora, motosserra, cortador e trator. A variável estudada mostrou estrutura de dependência espacial, o que permitiu o mapeamento por Krigagem. A partir de observações dos mapas foi possível definir zonas de manejo adequado de proteção para os trabalhadores, e pôde, portanto, definir planos de trabalho e equipamentos de proteção individual para as diferentes máquinas estudadas.

Cunha et al. (2012) também encontraram valores acima da NR-15 na operação de aração com os tratores avaliados, apresentando níveis de ruído medido à altura do ouvido do operador, acima do limite de $85 \mathrm{~dB}(\mathrm{~A})$ para 8 horas de exposição diária. A grande evolução dos tratores nos últimos anos não foi capaz de reduzir o ruído a níveis seguros de trabalho sem a utilização de protetores auriculares nos tratores não-cabinados, o que demonstra a necessidade do aprofundamento dos estudos de acústica nesta área e a importância das cabines.

Os cuidados em relação ao nível de ruído emitido pelo trator devem ser aguçados quando utilizado em operações estacionárias e ambientes fechados, sendo necessária a utilização de equipamentos de proteção auricular tanto para o operador da máquina quanto para os funcionários que trabalhem em distâncias prejudiciais. Os níveis de ruído foram superiores ao permitido pela legislação que é $85 \mathrm{~dB}$ para se desconsiderar a proteção auricular em uma jornada de trabalho de oito horas.

\section{Conclusões}

A variabilidade espacial do ruído em torno do trator teve maior alcance na plena aceleração com $31 \mathrm{~m}$. Os valores de ruído superiores a $85 \mathrm{~dB}$ (NR 15) foram encontrados numa distância de $7 \mathrm{~m}$ para rotação de trabalho e $11 \mathrm{~m}$ para plena aceleração em relação ao trator. Os valores de ruído encontrados nessas distâncias são considerados prejudiciais, para os operadores das máquinas e para indivíduos que permaneçam próximos ao trator, segundo a NR-15.

\section{Agradecimentos}

À Faculdade de Ciências Agronômicas UNESP Botucatu e ao grupo NEMPA (Núcleo de Máquinas e Pneus Agrícolas e Florestais) pela colaboração para o desenvolvimento desta pesquisa.

\section{Referências Bibliográficas}

ALVES, A. D. S.; COSTA, F. R. L.; CORTEZ, J. W.; DANTAS, A. C. S.; NAGAHAMA, H. J. Níveis de potência sonora emitidos por trator agrícola em condições estáticas e dinâmicas. Pesquisa Agropecuária Tropical, Goiânia-GO, v. 41, n. 1, p. 110-119, jan./mar. 2011.

AMBROSI, J. N.; MAGGI, M. F. Acidentes de trabalho relacionados às atividades agrícolas. Acta Iguazu, Cascavel-PR, v.2, n.1, p. 1-13, 2013

BRASIL. MINISTÉRIO DO TRABALHO E EMPREGO. Atividades e operações insalubres. NR 15 . Disponível em: < http://portal.mte.gov.br/legislacao/norma-regulamentadora-n-15-1.htm >. Acesso em: 16 de jan. 2014.

BRAVALHERI, A. C.; BERNARDO, L. A.; MIRANDA, M. A. M.; ANGELO, T. N.; PARAHYBA, V. E. S. Poluição sonora em ambientes da Unicamp. Revista Ciências do Ambiente On-Line, Campinas-SP, v. 6, n. 1, p. 1-7, 2010. 
CUNHA, J. P. A. R.; DUARTE, A. V.; SOUZA, C. M. A. Vibração e ruído emitidos por dois tratores agrícolas. Idesia, Chile, v. 30, n. 1, p. 25-34, 2012.

CUNHA, J. P. A. R.; TEODORO, R. E. F. Avaliação do nível de ruído em derriçadores e pulverizadores motorizados portáteis utilizados em lavouras de café. Bioscience Journal, Uberlândia-MG, v.22, n.3, p. 71-77, 2006.

DEUTSCH, C.V.; JOURNEL, A.G. GSLIB: Geostatistical software library and user's guide. 2nd ed. New York: Oxford University Press; 1998.

SILVA, A. F.; BARBOSA, A. P.; ZIMBACK, C. R. L.; LANDIM, P. Geostatistics and remote sensing methods in the classification of images of areas cultivated with citrus. Engenharia Agrícola, Jaboticabal-SP, v. 33, n. 6, p.1245-1256, 2013.
FERRAZ, G. A. S.; SILVA, F. C.; NUNES, R. A.; PONCIANO, P. F. Variabilidade espacial do ruído gerado por uma derriçadora portátil em lavoura cafeeira. Coffee Science, Lavras-MG, v. 8, n. 3, p. 276$283,2013$.

YANAGI JUNIOR, T.; SCHIASSI, L.; ROSSONI, D. F.; PONCIANO, P.F.; LIMA, R. R. Spatial variability of noise level in agricultural machines. Engenharia Agrícola, Jaboticabal-SP, v. 32, n. 2, p. 217-225, 2012.

YAMAMOTO, J. K. Cálculo de mapas de probabilidade diretamente dos pesos da krigagem ordinária. Geologia USP Série Científica, São Paulo-SP, v. 10, n. 1, p. 3-14, 2010.

ZIMBACK, C. R. L. Análise espacial de atributos químicos de solos para fins de mapeamento da fertilidade do solo. $2001.114 \mathrm{f}$. Tese (Livre-Docência) - Faculdade de Ciências Agronómicas, Universidade Estadual Paulista, Botucatu- SP, 2001. 